\title{
Masking Agents Evaluation for Lead Determination by Flow Injection-Hydride Generation-Atomic Fluorescence Spectrometry Technique: Effect of KI, L-Cysteine, and 1,10-Phenanthroline
}

\author{
Blanca G. Beltrán, ${ }^{1}$ Luz O. Leal, ${ }^{1}$ Laura Ferrer, ${ }^{2}$ and Víctor Cerdà ${ }^{2}$ \\ ${ }^{1}$ Environment and Energy Department, Advanced Materials Research Center (CIMAV) S. C., Miguel de Cervantes 120, \\ 31136 Chihuahua, CHIH, Mexico \\ ${ }^{2}$ Department of Chemistry, University of the Balearic Islands, Cra. Valldemossa km 7.5, 07122 Palma, Spain
}

Correspondence should be addressed to Luz O. Leal; luz.leal@cimav.edu.mx

Received 4 February 2016; Accepted 27 March 2016

Academic Editor: Spas D. Kolev

Copyright (C) 2016 Blanca G. Beltrán et al. This is an open access article distributed under the Creative Commons Attribution License, which permits unrestricted use, distribution, and reproduction in any medium, provided the original work is properly cited.

\begin{abstract}
Hydride generation (HG) of lead technique presents interferences from foreign ions of complex matrix samples. In order to minimize these interferences, the effect of masking agents such as KI, L-cysteine, and 1,10-phenanthroline was studied in the absence and in the presence of selected interfering species ( $\mathrm{As}, \mathrm{Cr}, \mathrm{Cu}$, and $\mathrm{Fe}$ ). Different modes of addition of masking agents were accomplished, that is, to either sample or $\mathrm{KBH}_{4}$ reducing solution. The lead determinations were performed using a flow injection analysis (FIA) system coupled to HG and atomic fluorescence spectrometry (AFS). The linearity of calibration curves (1$10 \mu \mathrm{g} \mathrm{Pb} \mathrm{L}{ }^{-1}$ ) was not affected by the addition of the masking agents. The use of $\mathrm{KI}$ in the reducing solution diminished interferences from concentrations of $\mathrm{As}$ and $\mathrm{Cu}$, while 1,10-phenanthroline showed a positive effect on the interference by As. Moreover, $\mathrm{Cr}$ and $\mathrm{Cu}$ appeared to be the most serious interfering ions for plumbane $\left(\mathrm{PbH}_{4}\right)$, because they drastically reduced the analytical signal of lead. Fe did not present any interference under the employed experimental conditions, even at high levels. The accuracy was established through the analysis of certified reference material (i.e., BCR-610, groundwater) using KI as masking agent. The detection limit reached by FIA-HG-AFS proposed methodology was $0.03 \mu \mathrm{g} \mathrm{Pb} \mathrm{L}{ }^{-1}$.
\end{abstract}

\section{Introduction}

The determination of ultra-traces of lead in environmental samples plays an important role in the pollution monitoring [1]. Among several techniques used to measure lead concentrations, atomic fluorescence spectrometry (AFS) has been widely used as a detection technique for the analysis of different kinds of biological and environmental samples $[2,3]$. However, in the case of the analytical determination of trace amounts of lead, the direct analysis is inadequate, and it is necessary to improve the sensitivity of AFS by using hydride generation (HG) of its volatile species $\left(\mathrm{PbH}_{4}\right)$ [4]. The hyphenation of HG for lead separation from the matrix sample $[5,6]$ with AFS detection exploiting a flow-based technique offers sensitive detection and fast operation [7].
Volatile hydrides of As, Sn, Sb, Cd, Se, Hg, and $\mathrm{Pb}$ [8] are usually generated using tetrahydroborate (THB) in acid medium $\left(\mathrm{HCl}, \mathrm{HNO}_{3}\right)$, which is capable of producing borane complexes [9]. Furthermore, volatile species arising out of the transition metals such as $\mathrm{Fe}, \mathrm{Cu}$, and $\mathrm{Cr}$ also can be formed. These vapour species are highly unstable and can readily form colloids or macro precipitates [10, 11].

In the case of $\mathrm{Pb}$, the generation of plumbane is achieved by using THB in combination with potassium ferricyanide $\mathrm{K}_{3}\left[\mathrm{Fe}(\mathrm{CN})_{6}\right]$, which is one of the most used additives improving the generation of plumbane $[4,12]$. The reaction of potassium ferricyanide with THB forms hydroboron intermediates which can react efficiently with $\mathrm{Pb}$ giving strong enhancement of plumbane generation reaction [13]. The generation of lead hydride is difficult and different from other 
hydride-forming elements because it is highly susceptible to suffering interferences, which can be produced by foreign ions present in sample matrices. $\mathrm{PbH}_{4}$ can only be achieved in the presence of oxidizing and chelating or masking agents (MA) [14]. These additives are chemical substances which are added to the reaction system in order to improve both the efficiency and the selectivity of plumbane generation [15].

Serious interferences derive from noble metals, transition metals (e.g., $\mathrm{Cu}, \mathrm{Fe}$, and $\mathrm{Cr}$ ), and hydride-forming elements (As), especially when they are present in great excess over the analyte [16].

The interference effects are acutely different and unpredictable, being dependent on the specific analyte-interfering couple, experimental conditions (acid and THB concentration, type of acid), the type and design of the apparatus (continuous flow, flow injection, and batch), detectors employed, and performances of the reactor and gas-liquid separation units of HG system [11, 15-17]. Different interference mechanisms have been set by categories as follows: analyte-foreign ion; analyte-product interference; hydrideforeign ion interference; hydride-product interference; THB depletion interference. Previous works have reported that most of these mechanisms are effective in explaining the interferences in $\mathrm{HG}[18,19]$.

The interferences can occur before or during formation of the hydride, in the separation of the volatile species from the liquid phase, and also during atomization [15]. Liquid-phase interferences are strictly related to the mechanism of HG with borane complexes; however these mechanisms are not clear enough [6]. Furthermore, gas-phases interferences can occur due to the formation of other hydrides, volatiles species of transition elements and aerosol transported with carrier gas [20].

The use of MA in HG technique for trace elements determination is one of the most important methods for the control of liquid-phase interferences generated by transition metals and hydride-forming elements, reducing interferences and maintaining the analytical sensitivity [21]. The mode of addition of MA has a great effect in the control of interfering processes, which could explain the discrepancies reported in the literature [22]. MA can be added on-line or as batch to reducing solution or to sample before or after $\mathrm{HG}$.

However, in the literature there have been scarce reported works about the lead determination by HG-AFS in environmental samples using MA in order to reduce or avoid interferences. Since details of operating conditions of HG reaction (e.g., acidification, reagent concentrations, order to add the $\mathrm{MA}$, and flow rates) are missing in the bibliography, the results about chemical interferences in plumbane generation are difficult to compare [23].

Several reagents such as L-cysteine, 1,10-phenanthroline, and potassium iodide (KI) were used as MA to reduce chemical interferences caused by foreign ions. L-Cysteine with $\mathrm{THB}$ played a role in both signal enhancement and interference control of germane-HG [24]. In addition, Lcysteine did not affect the hydride generation of Sn utilizing a reaction medium at lower acidities [25]. 1,10-Phenanthroline has been used as additive for the control of interferences in the determination of arsenic and selenium and it improved tolerance limits of $\mathrm{Ni}(\mathrm{II})$ and $\mathrm{Cu}(\mathrm{II})[26,27]$. Other works have described batch procedures by AFS for $\mathrm{Pb}(\mathrm{II})$ determination in vegetal and geological samples [28, 29]. Besides, interferences were avoided by the addition of phenanthroline-thiocyanate and oxalic acid as MA [14]. Some works have reported the addition of the KI to reducing solution of THB, which has been effective in the control of transition metal interferences $[30,31]$. This has been attributed to the catalytic effect of halide ions on the formation of hydrides. Furthermore, the addition of KI to THB solution in combination with thiourea as MA resulted in a suitable MA for selenium and tellurium determination [31].

To the best of our knowledge, at present, the use of KI, Lcysteine, and 1,10-phenanthroline as MA in plumbane generation has not been evaluated comparatively in order to abate the liquid-phase interferences caused by foreign ions. Thus, the main objective of this work is the evaluation of the abovementioned MA to solve the negative impact of $\mathrm{As}, \mathrm{Cu}, \mathrm{Fe}$, and $\mathrm{Cr}$ in the analytical signal of $\mathrm{Pb}$ by FIA-HG-AFS technique.

\section{Experimental Section}

2.1. Reagents. All chemicals used were of analytical reagent grade. For preparation of all solutions, Millipore-purified water was used. Glassware needed for lead determination was soaked in $10 \%(\mathrm{v} / \mathrm{v}) \mathrm{HNO}_{3}(65 \%)$ and rinsed with Millipore water.

Series of $\mathrm{Pb}, \mathrm{As}, \mathrm{Cu}, \mathrm{Cr}$, and $\mathrm{Fe}$ standard solutions were prepared by gradually diluting $1000 \mathrm{mg} \mathrm{L}^{-1}$ standard stock solutions from CENAM (National Metrology Center, Mexico) in $50 \mathrm{~mL}$ of $1.5 \%$ (v/v) $\mathrm{HCl}(36-38 \%)$ solution.

A $1 \% \mathrm{KBH}_{4}$ (98\%, Sigma-Aldrich) and $1.5 \%(\mathrm{~m} / \mathrm{v})$ $\mathrm{K}_{3}\left[\mathrm{Fe}(\mathrm{CN})_{6}\right](99.5 \%)$ solution as reducing solution were daily prepared with a $0.2 \% \mathrm{KOH}(87 \%)$ solution.

L-Cysteine (97\%), 1,10-phenanthroline (99\%), and KI (99.6\%) were used to prepare MA solutions. The L-cysteine and 1,10-phenanthroline solutions were added to standards solutions and were acquired from Sigma-Aldrich. KI was added to reducing solution $\mathrm{KBH}_{4}$.

Nitric and hydrochloric acids, potassium ferricyanide, potassium hydroxide, and potassium iodide were purchased from J.T.Baker, USA.

2.2. AFS Set-Up and Manifold. Measurements were accomplished by means of an atomic fluorescence spectrometer AF640 (Rayleigh Analytical Instrument Corp., Beijing, China). The instrument was equipped with a gas-liquid separator (GLS), which allows the separation of the $\mathrm{PbH}_{4}$ of the aqueous phase of the sample. A super-cathode lamp was used as radiation source $(\lambda=283 \mathrm{~nm})$. The manifold consists of a peristaltic pump with two sampling tubes $(1.59 \mathrm{~mm}$ id): one of them for reducing solution and the other one for sample/ carrier solution. The manifold comprises a holding coil (HC), a mixed module (MM), and a reaction coil (RC). An argon gas input was set after RC. In Table 1 are summarized the operating parameters of the AF-640.

Data collection and processing as well as the instrumental control were carried out with the manufacturer software AF6401.3 . 
TABLE 1: Operation parameters of AFS instrument and FIA system.

\begin{tabular}{lclc}
\hline \multicolumn{1}{c}{ AFS parameters } & & & Chemical conditions \\
\hline Argon flow rate $\left(\mathrm{mL} \mathrm{min}^{-1}\right)$ & 400 & $\mathrm{KBH}_{4}$ & $1 \%(\mathrm{~m} / \mathrm{v})$ \\
Delay time $(\mathrm{s})$ & 4 & $\mathrm{~K}_{3}\left[\mathrm{Fe}(\mathrm{CN})_{6}\right]$ & $1.5 \%(\mathrm{~m} / \mathrm{v})$ \\
Reading time $(\mathrm{s})$ & 22 & Carrier $\mathrm{HCl}$ & $1.5 \%(\mathrm{v} / \mathrm{v})$ \\
Load sample time $(\mathrm{s})$ & 8 & $\mathrm{HCl}$ medium for sample and standard solutions & $1.5 \%(\mathrm{v} / \mathrm{v})$ \\
Sample volume $(\mathrm{mL})$ & 1.3 & & \\
Sampling loading flow rate $\left(\mathrm{mL} \mathrm{min}^{-1}\right)$ & 8 & & \\
\hline
\end{tabular}

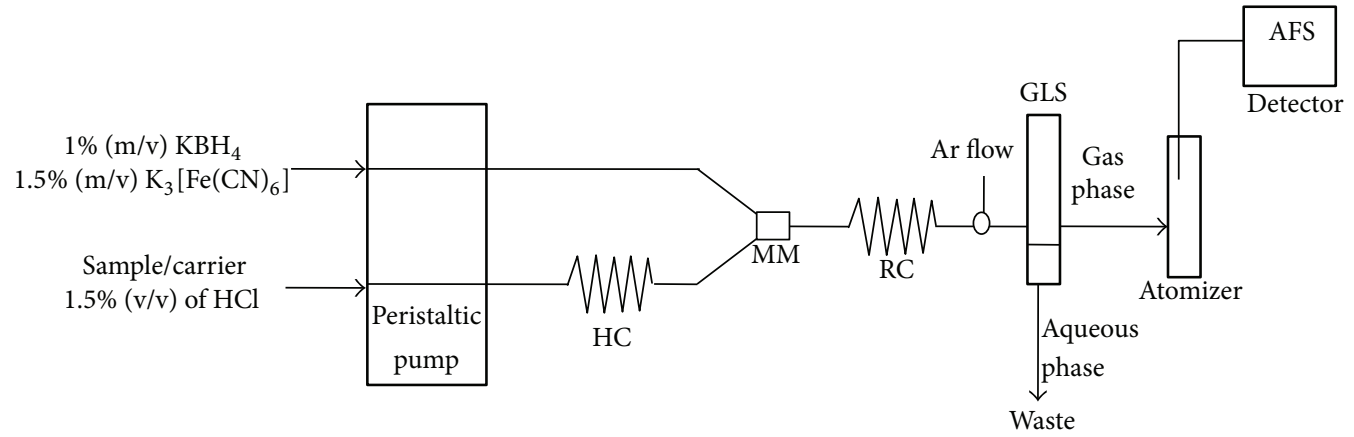

FIGURE 1: Schematic representation of flow-based hydride generation-atomic fluorescence spectrometry system, FIA-HG-AFS. HC: holding coil; MM: mixed module; RC: reaction coil; GLS: gas-liquid separator.

2.3. Working Conditions and Procedure. Since the efficiency of $\mathrm{HG}$ reaction, that is, the degree of the release of lead hydride in a reaction/separation cell and the transport to the detection system, depends critically on the adjustment of chemical and flow parameters, these conditions were optimized in a previous work [32]. The reagent concentrations were employed as follows: potassium ferricyanide solution was set in $1.5 \%(\mathrm{~m} / \mathrm{v})$, potassium borohydride solution was set in $1 \%(\mathrm{~m} / \mathrm{v})$, and hydrochloric acid solution was set in $1.5 \%$.

A scheme of FIA-HG-AFS system for $\mathrm{Pb}$ determination is showed in Figure 1. First, the sample is sucked into the HC, but it does not enter in the mixed module (MM); therefore the vapour has not been generated yet. At the same time the solutions of $\mathrm{KBH}_{4}$ and $\mathrm{K}_{3}\left[\mathrm{Fe}(\mathrm{CN})_{6}\right]$ are also impelled by the peristaltic pump and go inside to the RC. The peristaltic pump stops running; the sample collection is complete. The sample/carrier tube is manually transferred to the carrier. The carrier $(1.5 \% \mathrm{~m} / \mathrm{v} \mathrm{HCl})$ drives to the sample through a $\mathrm{MM}$ and then the sample is introduced into RC, where the hydride generation is performed. The volatile lead hydride and the hydrogen gas produced by the reaction are carried by the argon gas into the quartz furnace atomizer to form the Ar$\mathrm{H}_{2}$ flame.

2.4. Optimization of the Masking Agent Concentrations. The effect of MA on the lead analytical signal by FIA-HG-AFS was first tested in the absence of foreign ions, on the slope of calibration curves in a concentration range of $0-10 \mu \mathrm{g} \mathrm{L}^{-1}$ of $\mathrm{Pb}$. In addition, different concentrations of MA were utilized in each curve, to prove if there was loss of sensitivity in the method, namely, if the presence of MA caused them some kind of signal suppression. With these results, an adequate concentration of each MA was selected, which was utilized in the posterior experiments.

2.5. Effect of Masking Agents on the Plumbane Generation in Presence of Foreign Ions. The effect of MA on the analytical signal of lead was tested in presence of different concentrations of interferents, namely, $\mathrm{As}, \mathrm{Cu}, \mathrm{Cr}$, and $\mathrm{Fe}$, using a lead standard solution of $10 \mu \mathrm{g} \mathrm{L}^{-1}$ (Table 2). The concentration levels of each one of the foreign ions were set taking into account their concentration in environmental samples. Recoveries were evaluated in order to find the maximum tolerated concentration of these foreign ions in the $\mathrm{PbH}_{4}$ generation. The criterion to consider that an element does not interfere was that the variation of the analytical signal is lesser than $\pm 10 \%$. Finally, the interfering tolerated concentration in presence of MA was established.

2.6. Application of Masking Agents in BCR-610 Certified Reference Material. The use of MA in the determination of lead by HG-AFS was validated by the analysis of a certified reference material BCR-610 (groundwater) of the Community Bureau of Reference. The addition of KI to THB solution was carried out with the purpose of masking interferences, allowing the achievement of reaction conditions and obtaining results in agreement with the certified reference values.

\section{Results and Discussion}

3.1. Optimization of the Masking Agents Concentrations. In the absence of interfering species, KI produced a slight enhancement in the sensitivity, which is increasing as the KI concentration increases (Figure 2), due to the catalytic role 
TABLE 2: Assays carried out for foreign ions.

\begin{tabular}{|c|c|c|}
\hline Foreign ion & $\begin{array}{l}\text { Levels of concentration } \\
\left(\mu \mathrm{g} \mathrm{L}^{-1}\right)\end{array}$ & Masking agent (MA) \\
\hline Arsenic & $0,100,200,300$ & $\begin{array}{c}\text { Without MA } \\
\text { KI } \\
\text { L-Cysteine } \\
\text { 1,10-Phenanthroline }\end{array}$ \\
\hline Copper & $0,300,600,1000$ & $\begin{array}{c}\text { Without MA } \\
\text { KI } \\
\text { L-Cysteine } \\
\text { 1,10-Phenanthroline }\end{array}$ \\
\hline Chromium & $0,100,200,300$ & $\begin{array}{c}\text { Without MA } \\
\text { KI } \\
\text { L-Cysteine } \\
\text { 1,10-Phenanthroline }\end{array}$ \\
\hline Iron & $0,100,200,300,600,1000$ & Without MA \\
\hline
\end{tabular}

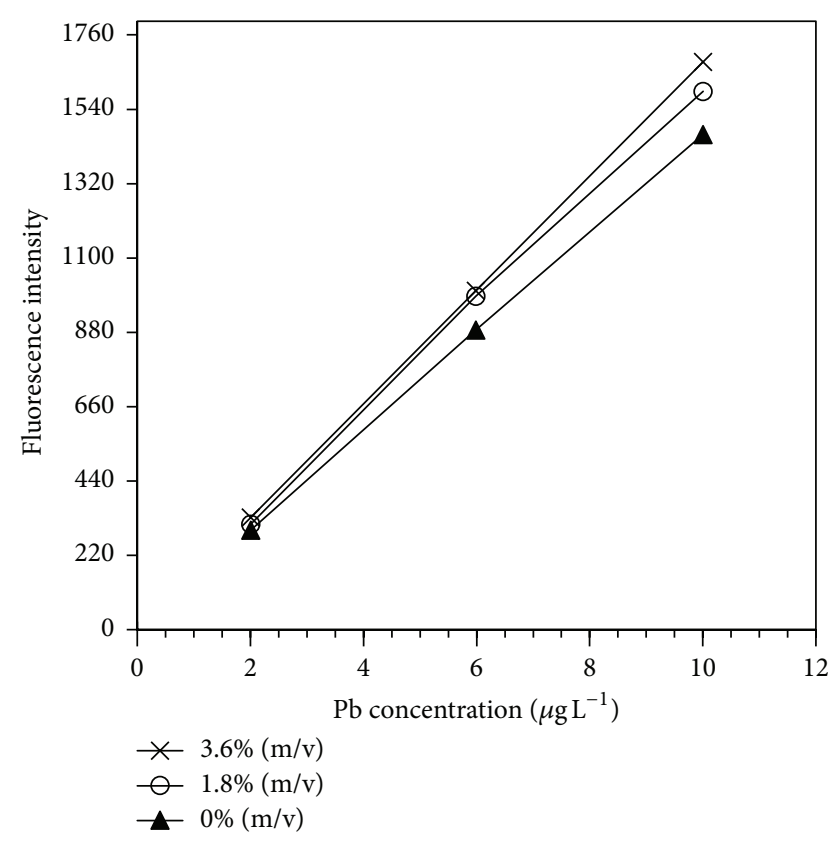

FIGURE 2: Calibration curves for lead obtained in the presence of different concentration of $\mathrm{KI}$ added to the reducing solution. Reaction conditions: $1 \%(\mathrm{~m} / \mathrm{v}) \mathrm{KBH}_{4}, 1.5 \%$ (v/v) $\mathrm{HCl}$, and $1.5 \%(\mathrm{~m} / \mathrm{v})$ $\mathrm{K}_{3}\left[\mathrm{Fe}(\mathrm{CN})_{6}\right]$.

of iodide [33], which is consistent with a previous study for hydrogen telluride generation [31]. Thus, a concentration of $1.8 \%(\mathrm{~m} / \mathrm{v})$ KI was selected for subsequent experiments with foreign ions, since at higher concentrations a major increase in the analytical signal was not observed.

Results showed that as L-cysteine concentration increased, the sensitivity decreased, and the values of the blanks were higher. Therefore, seeking a compromise between sensitivity and matrix interference, the selected concentration was $0.6 \%(\mathrm{~m} / \mathrm{v})$ (Figure 3).

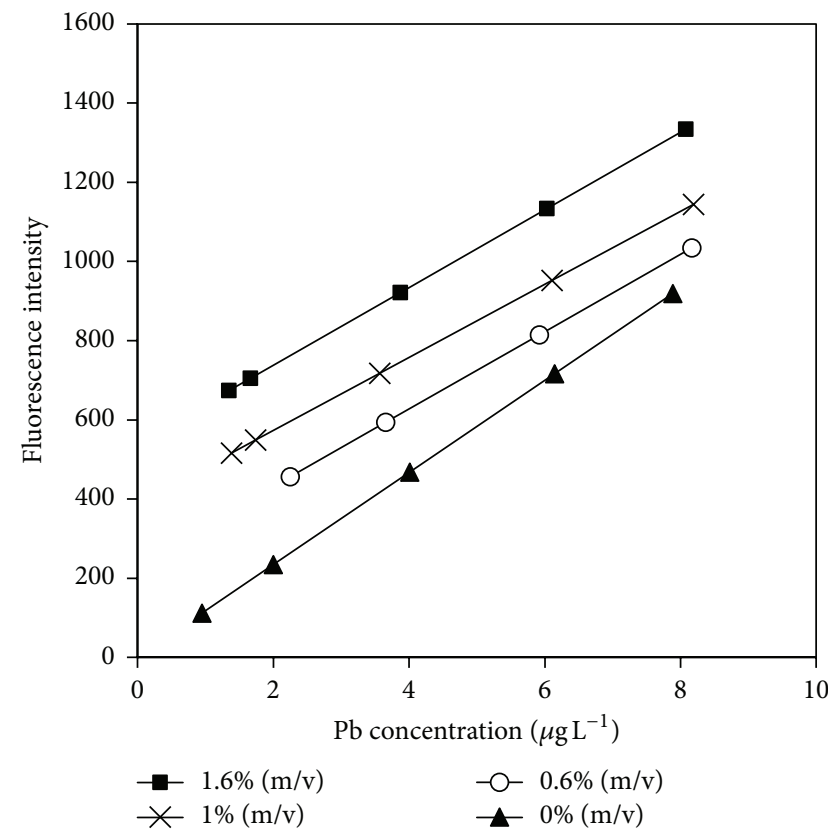

FIGURE 3: Calibration curves for lead obtained in the presence of different concentration of L-cysteine. Reaction conditions: $1 \%(\mathrm{~m} / \mathrm{v})$ $\mathrm{KBH}_{4}, 1.5 \%(\mathrm{v} / \mathrm{v}) \mathrm{HCl}$, and $1.5 \%(\mathrm{~m} / \mathrm{v}) \mathrm{K}_{3}\left[\mathrm{Fe}(\mathrm{CN})_{6}\right]$.

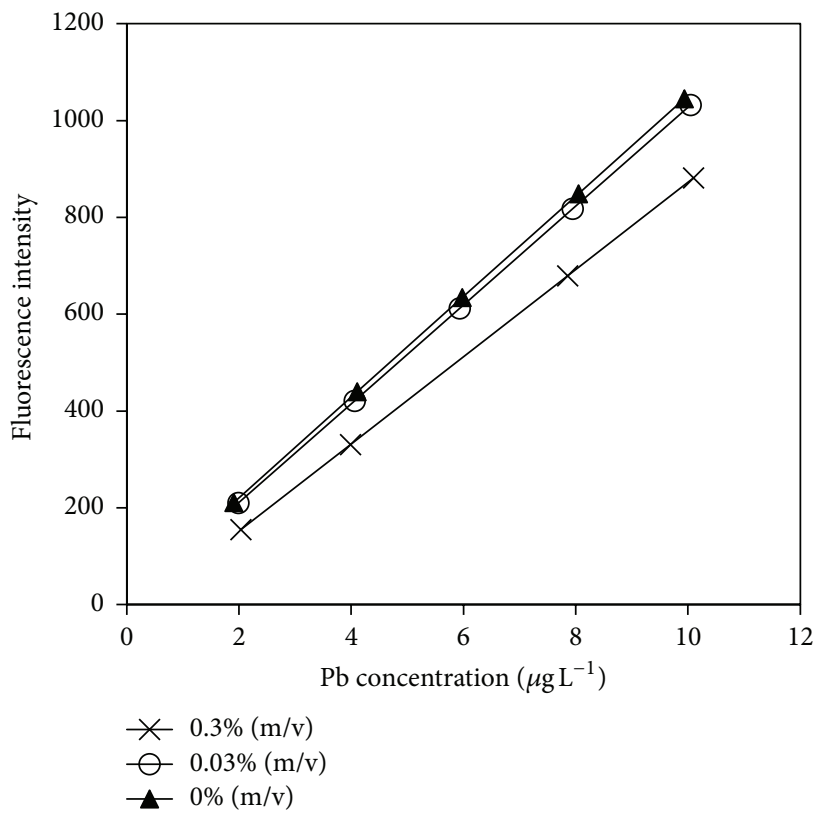

FIGURE 4: Calibration curves for lead obtained in the presence of different concentration of 1,10-phenanthroline. Reaction conditions: $1 \%(\mathrm{~m} / \mathrm{v}) \mathrm{KBH}_{4}, 1.5 \%(\mathrm{v} / \mathrm{v}) \mathrm{HCl}$, and $1.5 \%(\mathrm{~m} / \mathrm{v}) \mathrm{K}_{3}\left[\mathrm{Fe}(\mathrm{CN})_{6}\right]$.

Meanwhile, 1,10-phenanthroline was tested at two different concentrations. A concentration of $0.03 \%(\mathrm{~m} / \mathrm{v}) 1,10$ phenanthroline was selected, considering that the corresponding slope of the calibration curve remained almost parallel to that corresponding to the calibration curve without 1,10-phenanthroline (Figure 4). 


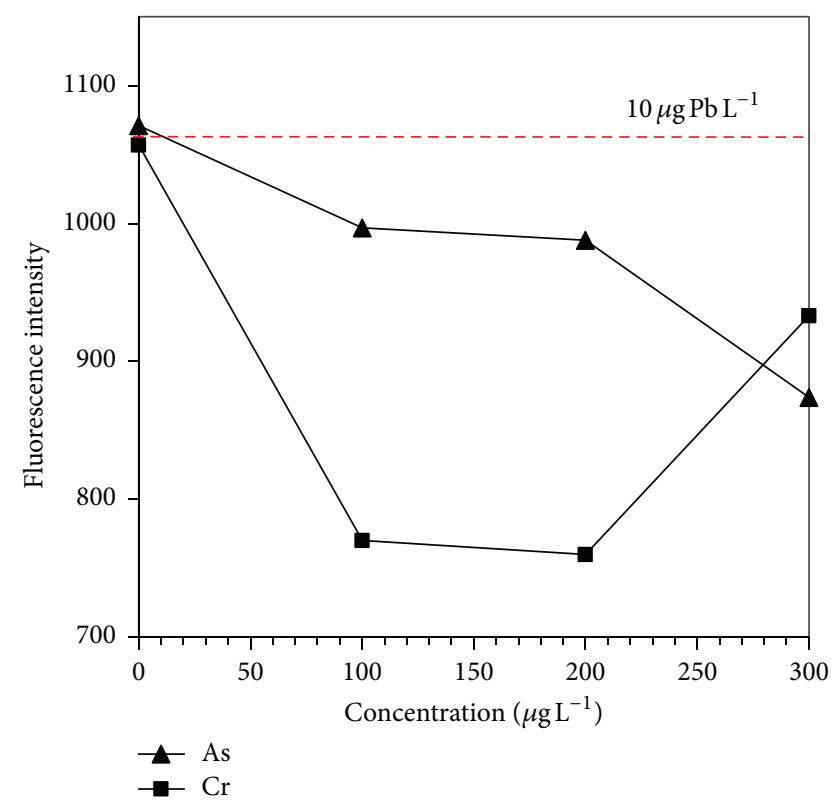

Figure 5: Effect of As and $\mathrm{Cr}$ concentrations on the fluorescence intensity of $\mathrm{Pb}$. Peak height measurements for $10 \mu \mathrm{g} \mathrm{Pb} \mathrm{L}{ }^{-1}$.

In summary, the concentrations of each MA used in the following tests to evaluate its effect on the foreign ions in the generation of plumbane were $1.8 \%(\mathrm{~m} / \mathrm{v}) \mathrm{KI}, 0.6 \%(\mathrm{~m} / \mathrm{v}) \mathrm{L}$ cysteine, and $0.03 \%(\mathrm{~m} / \mathrm{v}) 1,10$-phenanthroline.

\subsection{Effect of Masking Agents on Foreign Ions in the Plumbane} Generation. The depressive effects of $\mathrm{As}^{+5}, \mathrm{Cr}^{+6}, \mathrm{Cu}^{+2}$, and $\mathrm{Fe}^{+3}$ on the analytical signal (i.e., fluorescence intensity (FI)) obtained in the lead hydride generation of $10 \mu \mathrm{g} \mathrm{Pb} \mathrm{L}^{-1}$ are shown in Figures 5 and 6 . It is presumed that the mechanism of interference in the liquid phase is based on the interaction between tetrahydroborate and the metal ions [8]. It is important to mention that the transition metals such as Fe, $\mathrm{Cu}$, and $\mathrm{Cr}$ can also form volatile species by $\mathrm{HG}$ reactions, and gas-phase interferences could occur.

It should be pointed out that Fe did not cause a severe interference on the plumbane generation until a concentration tested of $1000 \mu \mathrm{g} \mathrm{Fe} \mathrm{L}{ }^{-1}$, which was even higher than that found in drinking and river water. The recoveries were maintained above $95 \%$. Then, the addition of any MA was not necessary.

The mechanism of the MA in HG is explained based on the analyte-MA and interferent-MA (additive) interactions [6]. Thus, different modes of addition of MA were accomplished, obtaining the best results when KI was added to the reducing solution $\mathrm{KBH}_{4}$ and L-cysteine and 1,10phenanthroline were added to the sample.

3.2.1. Arsenic. The reaction system for the plumbane generation is formed by $\mathrm{Pb}-\mathrm{THB}-\mathrm{K}_{3}\left[\mathrm{Fe}(\mathrm{CN})_{6}\right]-\mathrm{HCl}$ interactions. The addition of As affected the generation of $\mathrm{PbH}_{4}$, since the recoveries of $\mathrm{Pb}$ decreased until $82 \%$ in presence of $300 \mu \mathrm{g} \mathrm{As} \mathrm{L}^{-1}$ (Table 3). It is probably due to THB depletion

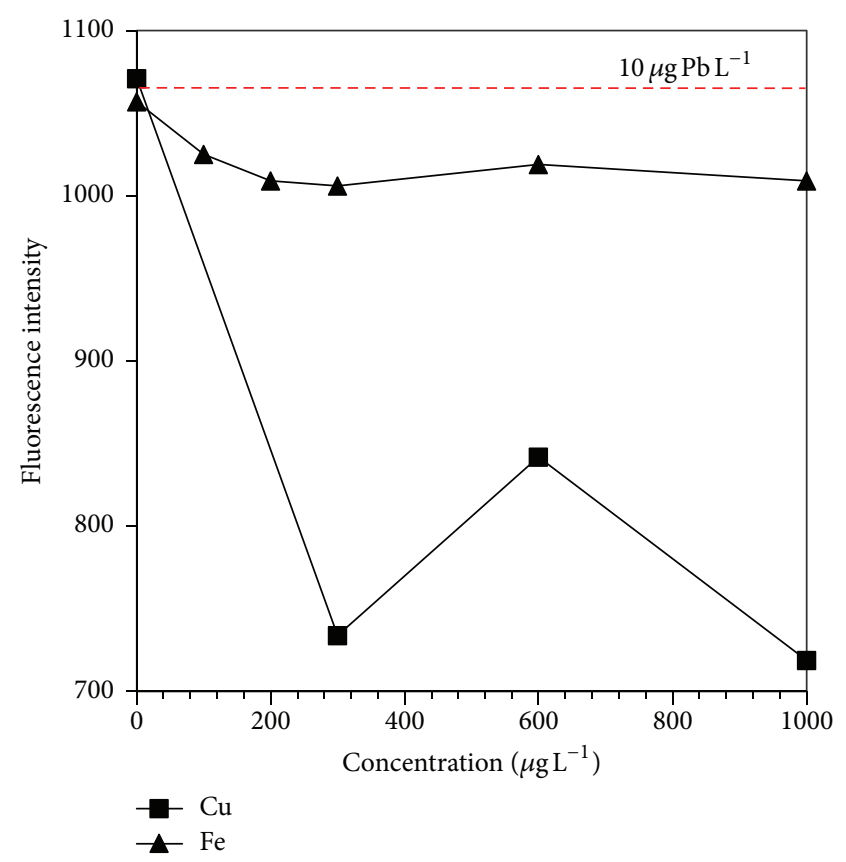

FIGURE 6: Effect of $\mathrm{Cu}$ and Fe concentrations on the fluorescence intensity of $\mathrm{Pb}$. Peak height measurements for $10 \mu \mathrm{g} \mathrm{Pb} \mathrm{L}{ }^{-1}$.

interference, in which this reagent is preferentially consumed by the interferent. Some analytical substrates such as As are more active than others and react with almost all the hydroboron species [6]. Thus, the rate of reaction of $\mathrm{Pb}$ with THB plays an important role on the generation of plumbane [34] and on the interference mechanism.

So, an inadequate concentration of THB could cause an inefficient reaction between $\mathrm{THB}$ and $\mathrm{K}_{3}\left[\mathrm{Fe}(\mathrm{CN})_{6}\right]$ and at the same time diminishes the borane complex intermediates, which are highly effective in the generation of plumbane [13].

However, it was found that it is possible to restore the lead analytical signal by the addition of KI to the reducing solution, obtaining $92 \%$ of recovery at the same concentration of As. Thus, a concentration of $300 \mu \mathrm{g} \mathrm{As} \mathrm{L^{-1 }}$ was set as the tolerance limit concentration, utilizing KI.

L-Cysteine failed to have a notorious masking effect, because the analytical signal of $\mathrm{Pb}$ was decreased in the presence of each one of the As concentrations tested in the experiments. L-Cysteine could have a masking effect by two proposed mechanisms. First, L-cysteine-THB complexes can be formed with L-cysteine and $\mathrm{KBH}_{4}$ reducing solution, which could be precursors to improvement of the HG efficiency of the target analyte [6]. On the other hand, L-cysteineanalyte complexes also can be formed, which are promoted at lower acidities, whereas L-cysteine-THB complexes are formed at higher acidities [25]. Following this approach and considering the low acidities conditions for plumbane generation, L-cysteine-THB could not be formed. On the other hand, the formation of the L-cysteine-analyte complexes was not favoured, even with favourable acidic conditions, since a masking effect for arsenic interference was not observed. 
TABLE 3: Results of the effect of foreign ions and masking agents on the analytical signal of $10 \mu \mathrm{gb} \mathrm{L}^{-1}$.

\begin{tabular}{|c|c|c|c|c|c|c|c|c|}
\hline $\begin{array}{l}\text { Foreign ion } \\
\text { concentration } \\
\left(\mu \mathrm{gL}^{-1}\right) \\
\end{array}$ & $\begin{array}{l}{ }^{\mathrm{a}} \mathrm{FI} \text { without } \\
\text { masking agent }\end{array}$ & $\begin{array}{c}\text { Recovery } \\
(\%)\end{array}$ & FI with KI & $\begin{array}{c}\text { Recovery } \\
(\%)\end{array}$ & $\begin{array}{c}\text { FI with } \\
\text { L-cysteine }\end{array}$ & $\begin{array}{c}\text { Recovery } \\
(\%)\end{array}$ & FI with 1,10-phenanthroline & $\begin{array}{c}\text { Recovery } \\
(\%)\end{array}$ \\
\hline \multicolumn{9}{|l|}{${ }^{\mathrm{b}}$ Arsenic } \\
\hline 0 & $1071 \pm 4$ & & $1036 \pm 2$ & & $1026 \pm 2$ & & $1089 \pm 12$ & \\
\hline 100 & $997 \pm 3$ & 93 & $1043 \pm 6$ & 101 & $995 \pm 5$ & 97 & $1097 \pm 7$ & 101 \\
\hline 200 & $988 \pm 7$ & 92 & $968 \pm 5$ & 93 & $844 \pm 9$ & 82 & $1016 \pm 10$ & 93 \\
\hline 300 & $874 \pm 0.2$ & 82 & $887 \pm 3$ & 92 & $681 \pm 4$ & 66 & $1009 \pm 8$ & 93 \\
\hline \multicolumn{9}{|l|}{${ }^{\mathrm{b}}$ Copper } \\
\hline 0 & $1071 \pm 9$ & & $1036 \pm 11$ & & $1026 \pm 2$ & & $1071 \pm 9$ & \\
\hline 300 & $734 \pm 5$ & 69 & $935 \pm 7$ & 90 & $631 \pm 5$ & 61 & $1442 \pm 17$ & 135 \\
\hline 600 & $842 \pm 7$ & 79 & $842 \pm 7$ & 90 & $627 \pm 25$ & 61 & $1442 \pm 25$ & 135 \\
\hline 1000 & $719 \pm 4$ & 67 & $719 \pm 4$ & 85 & $477 \pm 2$ & 46 & $1395 \pm 17$ & 130 \\
\hline \multicolumn{9}{|l|}{${ }^{\mathrm{b}}$ Chromium } \\
\hline 0 & $1057 \pm 4$ & & $1036 \pm 11$ & & $950 \pm 4$ & & $1071 \pm 9$ & \\
\hline 100 & $770 \pm 9$ & 73 & $755 \pm 9$ & 73 & $763 \pm 3$ & 80 & $768 \pm 7$ & 72 \\
\hline 200 & $760 \pm 12$ & 72 & $762 \pm 2$ & 73 & $747 \pm 12$ & 79 & $768 \pm 16$ & 72 \\
\hline 300 & $933 \pm 13$ & 88 & $932 \pm 1$ & 90 & $675 \pm 5$ & 71 & $768 \pm 20$ & 72 \\
\hline \multicolumn{9}{|l|}{${ }^{\mathrm{b}}$ Iron } \\
\hline 0 & $1057 \pm 4$ & & & & & & & \\
\hline 100 & $1025 \pm 16$ & 96 & & & & & & \\
\hline 200 & $1009 \pm 13$ & 95 & & & & & & \\
\hline 300 & $1006 \pm 8$ & 95 & & & & & & \\
\hline 600 & $1019 \pm 17$ & 96 & & & & & & \\
\hline 1000 & $1009 \pm 7$ & 95 & & & & & & \\
\hline
\end{tabular}

${ }^{\mathrm{a}} \mathrm{FI}$ : fluorescence intensity.

${ }^{\mathrm{b}}$ Measurements reported as the mean $\pm \mathrm{SD}(n=3)$.

Otherwise, 1,10-phenanthroline as MA had the same effect of $\mathrm{KI}$, improving the $\mathrm{Pb}$ analytical signal until $93 \%$ at $300 \mu \mathrm{g} \mathrm{L}^{-1}$ As concentration. Previous work has reported the use of 1,10-phenanthroline as MA, which can react with $\mathrm{K}_{3}\left[\mathrm{Fe}(\mathrm{CN})_{6}\right]$, maintaining the reaction conditions for plumbane generation [14].

3.2.2. Copper. Copper is recognized as a species able to produce a serious interference in the chemical generation of volatile species of hydride-forming elements [15]. In addition, $\mathrm{Cu}$ can also be converted into a volatile species and a noticeable aspect is that in its determination by $\mathrm{HG}$ it is markedly free from interference effects [35].

Low $\mathrm{Pb}$ recoveries were obtained as a result of the presence of different $\mathrm{Cu}$ concentrations tested (Figure 6). This fact could be explained based on the reagent- (THB-) interferent interaction; that is to say, the $\mathrm{Cu}$ concentration increases the rate of tetrahydroborate hydrolysis causing incomplete formation of the $\mathrm{Pb}$ hydride [30]. The presence of $\mathrm{Cu}$ can lead to the formation of THB-interferent complexes, which can involve toward the formation of reaction products of the interferent [15]. These products could cause an interference of the type hydride-product interference, in which the plumbane could be captured by foreign species (products of the interferent) [36].

The use of $\mathrm{KI}$ allowed improving the $\mathrm{Pb}$ maximum tolerance limit until $600 \mu \mathrm{g} \mathrm{Cu} \mathrm{L}{ }^{-1}$ (Table 3). It has been reported in previous works that $\mathrm{KI}$ can mask the $\mathrm{Cu}$ ion interference due to the formation and precipitation of $\mathrm{CuI}$ or due to the possible presence of other species in solution such as $\mathrm{Cu}$ in ground state, $I_{2}$, or a combination of them [21, 30, 37]. No precipitate in this work was observed. An explanation of this could be the chemical conditions (sample acidity, KI and $\mathrm{Cu}^{+2}$ concentrations) used in this work. In a previous study for selenium determination [21], the sample acidity was 5-16 times higher than that presented in this work and KI concentration was 5 times higher, whereas the $\mathrm{Cu}^{+2}$ concentrations tested were about 33-1000 times higher than those assayed in this work.

Thus, based on the literature cited above, the additiveinterferent interaction (i.e., $\mathrm{KI}$ and $\mathrm{Cu}$ ) could cause the formation of complex and redox reactions [15]. A concentration of $600 \mu \mathrm{g} \mathrm{Cu} \mathrm{L}^{-1}$ was set as the tolerance limit concentration utilizing $\mathrm{KI}$ as MA.

L-Cysteine did not have a MA effect on the $\mathrm{Cu}$ ions at the assayed concentrations. It should be noted that both MA 
and interferent produced a perturbation on the plumbane reaction system. The experiment results were displayed in Figure 3 and Table 3.

The 1,10-phenanthroline increased the analytical signal of lead, obtaining recoveries outside of the tolerated limit of interferences set in $\pm 10 \%$. Reagent-additive interaction can modify the mechanism and the kinetics of hydrolysis of borane reagent allowing the formation of additiveborane complexes [15]. However, an interaction between 1,10phenanthroline and $\mathrm{K}_{3}\left[\mathrm{Fe}(\mathrm{CN})_{6}\right]$ can also be considered [14].

3.2.3. Chromium. The liquid-phase interference mechanism considered for transitions metals such as $\mathrm{Cr}$ is one in which reactions between THB, analyte, and interfering ion conduced to the formation of metal colloids/metal borides. These chemical species have interaction with the analyte hydride causing interferences [6].

In this study, $\mathrm{Cr}$ appeared to be one of the most serious interfering ions for plumbane generation, because its presence causes lead recoveries between 73 and $88 \%$ (Table 3 and Figure 5). There is no improvement on the analytical signal of lead, since all MA had almost the same behaviour as the standard solutions in which MA were not used. Thus, it could be inferred that none of the MA were effective on different concentrations tested of $\mathrm{Cr}$ (Table 3). However, KI showed a slight improvement in the solution that contained $300 \mu \mathrm{g} \mathrm{L}^{-1}$ of $\mathrm{Cr}$ ( $90 \%$ of lead recovery).

\subsection{Validation with BCR-610 Certified Reference Material} Using KI as Masking Agent. The BCR-610 certified reference material was used to validate the use of MA in lead determination exploiting FIA-HG-AFS system. A " $t$-" test was applied in order to establish the statistical significance of results.

First, a direct analysis of BCR-610, that is, without MA, was performed. The results showed significant differences, which were found at confidence level of $95 \%$, between the certified value of $7.78 \pm 0.13 \mu \mathrm{g} \mathrm{Pb} \mathrm{L}^{-1}$ and the obtained value of $6.58 \pm 0.07 \mu \mathrm{g} \mathrm{Pb} \mathrm{L}^{-1}$. The low recovery can be due to the contents of As and Cu in BCR-610, 10.8 and $45.7 \mu \mathrm{g} \mathrm{L}^{-1}$, respectively. In addition, double peaks were obtained in the lead measurement, which is typical of interference phenomena and it is due to the slower rate of formation of one of the interfering species that is formed with a slower rate in respect to the analyte hydride [38]. However, with the use of KI as MA only one peak was observed and a value of $7.75 \pm 0.08 \mu \mathrm{g} \mathrm{Pb} \mathrm{L}^{-1}$ was achieved. Thus, this result was in agreement with the certified value and also indicated the positive effect of $\mathrm{KI}$ in the control of interference generated by relatively high concentration of $\mathrm{As}$ and $\mathrm{Cu}$.

\section{Conclusions}

The evaluation of MA and their effects in minimizing interferences in the plumbane generation, exploiting AFS as detector, was carried out. Excepting Fe, which did not cause interference on the plumbane generation even at a high concentration, the rest of the foreign ions tested, that is, $\mathrm{As}, \mathrm{Cu}$, and $\mathrm{Cr}$, promoted interferences in absence of
MA. THB depletion interference was caused by the presence of As. Transition metals such as $\mathrm{Cu}$ and $\mathrm{Cr}$ were the most serious interfering ions because they drastically reduced the analytical signal of lead, due probably to two types of interferences: hydride-product interference and hydride-ion interference. The sensitivity of the method was not affected with the use of KI and 1,10-phenanthroline, since no changes occurred in the slope of the calibration curves for both MA. On the other hand, L-cysteine produced high values of the blanks and a decrease in sensitivity. In addition, it had no effect at any concentration tested of the foreign ions. KI added to the reducing solution $\left(\mathrm{KBH}_{4}\right)$ diminishes As and $\mathrm{Cu}$ interferences. 1,10-Phenanthroline as MA had a slight positive effect for As, but it did not have effect for $\mathrm{Cu}$. Despite the fact that the $\mathrm{Pb}$ analytical signal was increased in presence of $\mathrm{Cu}$ with 1,10-phenanthroline, the recoveries were out of the tolerated limit range of interferences, probably because of an interaction between 1,10-phenanthroline and THB or its interaction with $\mathrm{K}_{3}\left[\mathrm{Fe}(\mathrm{CN})_{6}\right]$. The presence of MA did not have effect in the interference caused by $\mathrm{Cr}$. The determination of lead at trace levels in the BCR-610 (groundwater) certified reference material was satisfactory using KI as MA.

\section{Competing Interests}

The authors declare that they have no competing interests.

\section{Acknowledgments}

This study was supported by the National Council of Science and Technology in Mexico (CONACYT) and the Government of Chihuahua State (Project FOMIX CHIH-2013-C03194659) as well as the Spanish Ministry of Economy and Competitiveness (Project CTQ2013-47461-R) cofinanced by FEDER funds. B. Beltrán acknowledges CONACYT for the doctoral grant.

\section{References}

[1] M. Soylak, F. Armagan Aydin, S. Saracoglu, L. Elci, and M. Dogan, "Chemical analysis of drinking water samples from Yozgat, Turkey," Polish Journal of Environmental Studies, vol. 11, no. 2, pp. 151-156, 2002.

[2] I. B. Karadjova, L. Lampugnani, A. D’Ulivo, M. Onor, and D. L. Tsalev, "Determination of lead in wine by hydride generation atomic fluorescence spectrometry in the presence of hexacyanoferrate(III)," Analytical and Bioanalytical Chemistry, vol. 388, no. 4, pp. 801-807, 2007.

[3] H. Wu, Y. Jin, M. Luo, and S. Bi, "A simple and sensitive flowinjection on-line preconcentration coupled with hydride generation atomic fluorescence spectrometry for the determination of ultra-trace lead in water, wine, and rice," Analytical Sciences, vol. 23, no. 9, pp. 1109-1112, 2007.

[4] J. Kratzer, "Ultratrace determination of lead by hydride generation in atomizer trapping atomic absorption spectrometry: optimization of plumbane generation and analyte preconcentration in a quartz trap-and-atomizer device," Spectrochimica Acta Part B Atomic Spectroscopy, vol. 71-72, pp. 40-47, 2012. 
[5] Ü. Ay and E. Henden, "Interferences in the quartz tube atomizer during arsenic and antimony determination by hydride generation atomic absorption spectrometry," Spectrochimica Acta Part B: Atomic Spectroscopy, vol. 55, no. 7, pp. 951-958, 2000.

[6] A. R. Kumar and P. Riyazuddin, "Chemical interferences in hydride-generation atomic spectrometry," TrAC Trends in Analytical Chemistry, vol. 29, no. 2, pp. 166-176, 2010.

[7] L. O. Leal, R. Forteza, and V. Cerdà, "Speciation analysis of inorganic arsenic by a multisyringe flow injection system with hydride generation-atomic fluorescence spectrometric detection," Talanta, vol. 69, no. 2, pp. 500-508, 2006.

[8] A. D'Ulivo, L. Lampugnani, and R. Zamboni, "Interference of copper, silver and gold in the determination of selenium by hydride generation atomic fluorescence spectrometry: an approach to the studies of transition metal interferences," Journal of Analytical Atomic Spectrometry, vol. 6, no. 7, pp. 565$571,1991$.

[9] E. Bolea, F. Laborda, M. A. Belarra, and J. R. Castillo, "Interferences in electrochemical hydride generation of hydrogen selenide," Spectrochimica Acta Part B: Atomic Spectroscopy, vol. 56, no. 12, pp. 2347-2360, 2001.

[10] T. Matoušek, "The efficiency of chemical vapour generation of transition and noble metals," Analytical and Bioanalytical Chemistry, vol. 388, no. 4, pp. 763-767, 2007.

[11] Y.-L. Feng, R. E. Sturgeon, J. W. Lam, and A. D'Ulivo, “Insights into the mechanism of chemical vapor generation of transition and noble metals," Journal of Analytical Atomic Spectrometry, vol. 20, no. 4, pp. 255-265, 2005.

[12] E. Vereda Alonso, M. T. Siles Cordero, A. García de Torres, and J. M. Cano Pavón, "Lead ultra-trace on-line preconcentration and determination using selective solid phase extraction and electrothermal atomic absorption spectrometry: applications in seawaters and biological samples," Analytical and Bioanalytical Chemistry, vol. 385, no. 7, pp. 1178-1185, 2006.

[13] A. D’Ulivo, M. Onor, R. Spiniello, and E. Pitzalis, "Mechanisms involved in chemical vapor generation by aqueous tetrahydroborate(III) derivatization: role of hexacyanoferrate(III) in plumbane generation," Spectrochimica Acta Part B: Atomic Spectroscopy, vol. 63, no. 8, pp. 835-842, 2008.

[14] L. Zheng, L. Lin, L. Zhu, and M. Jiang, "Investigation of cobalt interference on lead hydride generation with tetrahydroborate(III) in the presence of hexacyanoferrate(III)," Spectrochimica Acta Part B: Atomic Spectroscopy, vol. 64, no. 3, pp. 222-228, 2009.

[15] A. D’Ulivo, "Mechanism of generation of volatile species by aqueous boranes: towards the clarification of most controversial aspects," Spectrochimica Acta Part B: Atomic Spectroscopy, vol. 65, no. 5, pp. 360-375, 2010.

[16] P. Pohl, P. Jamroz, M. Welna, A. Szymczycha-Madeja, and K. Greda, "Chemical-vapor generation of transition metals through the reaction with tetrahydroborate in recent achievements in analytical atomic spectrometry," TrAC-Trends in Analytical Chemistry, vol. 59, pp. 144-155, 2014.

[17] L. Elçi, Z. Arslan, and J. F. Tyson, "Determination of lead in wine and rum samples by flow injection-hydride generation-atomic absorption spectrometry," Journal of Hazardous Materials, vol. 162, no. 2-3, pp. 880-885, 2009.

[18] B. Welz and M. Melcher, "Mechanisms of transition metal interferences in hydride generation atomic-absorption spectrometry. Part 2. Influence of the valency state of arsenic on the degree of signal depression caused by copper, iron and nickel," Analyst, vol. 109, no. 5, pp. 573-575, 1984.
[19] D. Bax, J. Agterdenbos, E. Worrell, and J. B. Kolmer, “The mechanism of transition metal interference in hydride generation atomic absorption spectrometry," Spectrochimica Acta-Part B: Atomic Spectroscopy, vol. 43, no. 9-11, pp. 1349-1354, 1988.

[20] J. Dědina, "Atomization of volatile compounds for atomic absorption and atomic fluorescence spectrometry: on the way towards the ideal atomizer," Spectrochimica Acta Part B: Atomic Spectroscopy, vol. 62, no. 9, pp. 846-872, 2007.

[21] A. D’Ulivo, L. Gianfranceschi, L. Lampugnani, and R. Zamboni, "Masking agents in the determination of selenium by hydride generation technique," Spectrochimica Acta Part B: Atomic Spectroscopy, vol. 57, no. 12, pp. 2081-2094, 2002.

[22] R. Bye, "Interferences from bivalent cations in the determination of selenium by hydride-generation and atomic-absorption spectrometry. A discussion of the claim that the metal ions are reduced to the metallic state by sodium borohydride," Talanta, vol. 33, no. 8, pp. 705-706, 1986.

[23] P. Pohl and W. Zyrnicki, "Study of chemical and spectral interferences in the simultaneous determination of As, Bi, Sb, Se and Sn by hydride generation inductively coupled plasma atomic emission spectrometry," Analytica Chimica Acta, vol. 468, no. 1, pp. 71-79, 2002.

[24] I. D. Brindle and X.-C. Le, "Reduction of interferences in the determination of germanium by hydride generation and atomic emission spectrometry," Analytica Chimica Acta, vol. 229, pp. 239-247, 1990.

[25] E. Pitzalis, D. Ajala, M. Onor, R. Zamboni, and A. D’Ulivo, "Chemical vapor generation of arsane in the presence of Lcysteine. Mechanistic studies and their analytical feedback," Analytical Chemistry, vol. 79, no. 16, pp. 6324-6333, 2007.

[26] C. C. Y. Chan and R. S. Sadana, "Determination of arsenic and selenium in environmental samples by flow-injection hydride generation atomic absorption spectrometry," Analytica Chimica Acta, vol. 270, no. 1, pp. 231-238, 1992.

[27] H. Chen, W. Yao, D. Wu, and I. D. Brindle, "Determination of tin in steels by non-dispersive atomic fluorescence spectrometry coupled with flow-injection hydride generation in the presence of L-cysteine," Spectrochimica Acta-Part B Atomic Spectroscopy, vol. 51, no. 14, pp. 1829-1836, 1996.

[28] S. J. Hill, S. Chenery, J. B. Dawson et al., "Advances in atomic emission, absorption and fluorescence spectrometry, and related techniques," Journal of Analytical Atomic Spectrometry, vol. 15, no. 6, pp. 763-805, 2000.

[29] P. Zhang and Z. Hu, "Conditions for determination of lead in geological samples with hydride generation absorption spectrometry," Fenxi Huaxue, vol. 15, pp. 404-408, 1987.

[30] J. Agterdenbos and D. Bax, "Mechanisms in hydride generation AAS," Fresenius' Zeitschrift für Analytische Chemie, vol. 323, no. 7, pp. 783-787, 1986.

[31] A. D’Ulivo, K. Marcucci, E. Bramanti, L. Lampugnani, and R. Zamboni, "Studies in hydride generation atomic fluorescence determination of selenium and tellurium. Part 1: self interference effect in hydrogen telluride generation and the effect of KI," Spectrochimica acta-Part B: Atomic spectroscopy, vol. 55, no. 8, pp. 1325-1336, 2000.

[32] B. G. Beltrán, L. O. Leal, L. Ferrer, and V. Cerdà, “Determination of lead in complex sample matrices by atomic fluorescence spectrometry: optimisation of online hydride generation," International Journal of Environmental Analytical Chemistry, vol. 95, no. 11, pp. 1054-1065, 2015. 
[33] J. Agterdenbos, J. T. Van Elteren, D. Bax, and J. P. Ter Heege, "The determination of selenium with hydride generation AASIV. Application to coal analysis," Spectrochimica Acta Part B: Atomic Spectroscopy, vol. 41, no. 4, pp. 303-316, 1986.

[34] V. Yilmaz, Z. Arslan, O. Hazer, and H. Yilmaz, "Selective solid phase extraction of copper using a new $\mathrm{Cu}(\mathrm{II})$-imprinted polymer and determination by inductively coupled plasma optical emission spectroscopy (ICP-OES)," Microchemical Journal, vol. 114, pp. 65-72, 2014.

[35] R. E. Sturgeon, J. Liu, V. J. Boyko, and V. T. Luong, "Determination of copper in environmental matrices following vapor generation," Analytical Chemistry, vol. 68, no. 11, pp. 1883-1887, 1996.

[36] J. Dedina and D. L. Tsalev, Hydrides; Atomic Absorption Spectroscopy, John Wiley \& Sons, Chichester, UK, 1st edition, 1995.

[37] J. Agterdenbos and D. Bax, "Study of interferences by transition metal ions in hydride generation atomic absorption spectrometry of antimony," Analytical Chimical Acta, vol. 244, pp. 129-134, 1991.

[38] B. Welz and M. Sperling, Frontmatter: Atomic Absorption Spectrometry, Wiley-VCH Verlag GmbH, Weinheim, Germany, 3rd edition, 2007. 

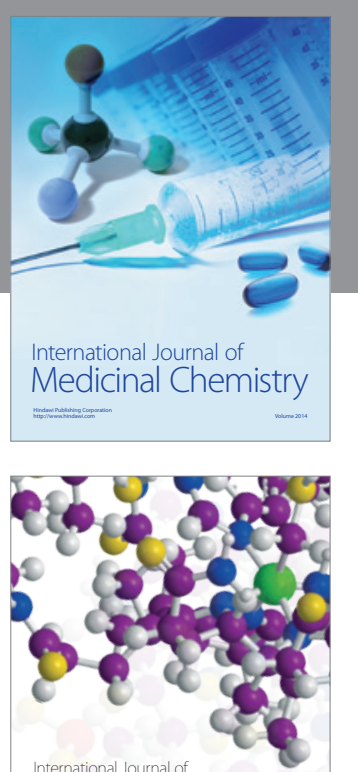

Carbohydrate Chemistry

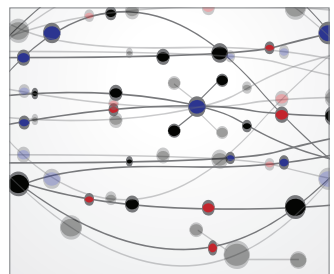

The Scientific World Journal
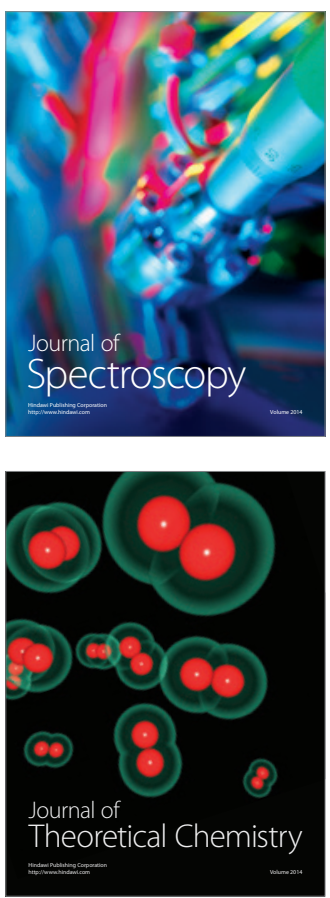
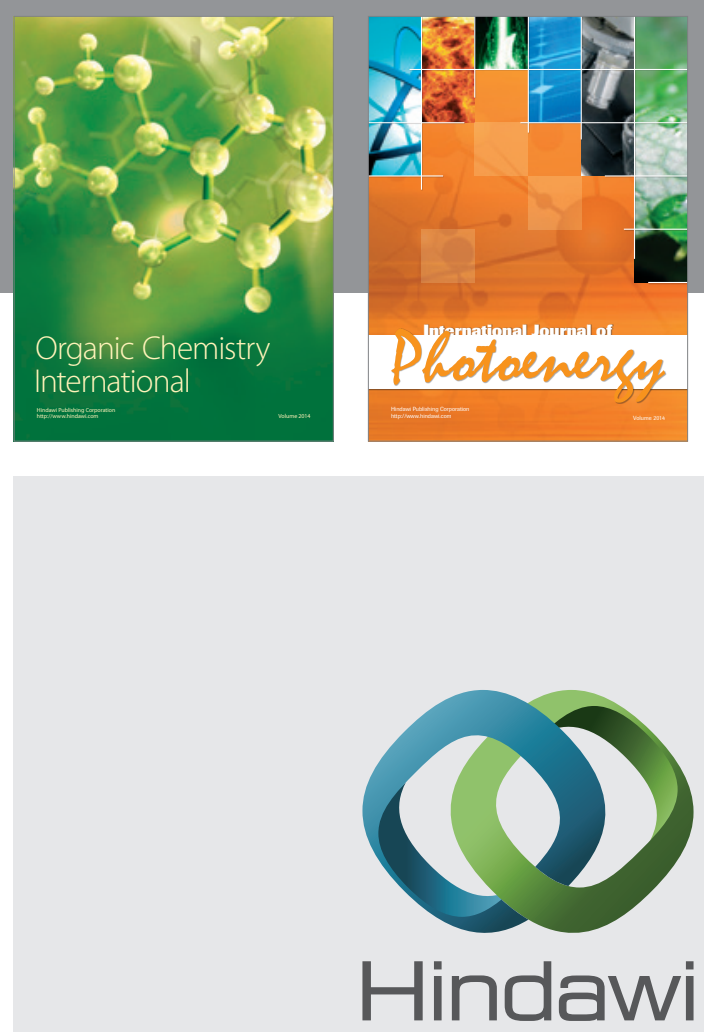

Submit your manuscripts at

http://www.hindawi.com

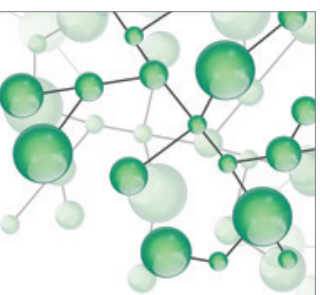

International Journal of

Inorganic Chemistry

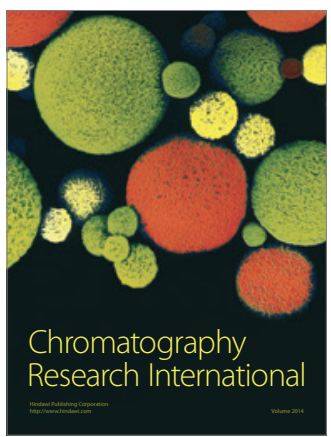

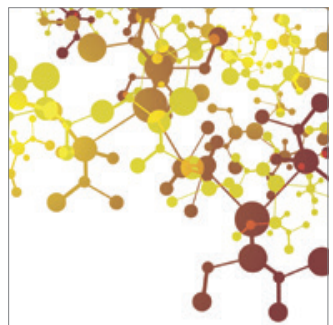

Applied Chemistry
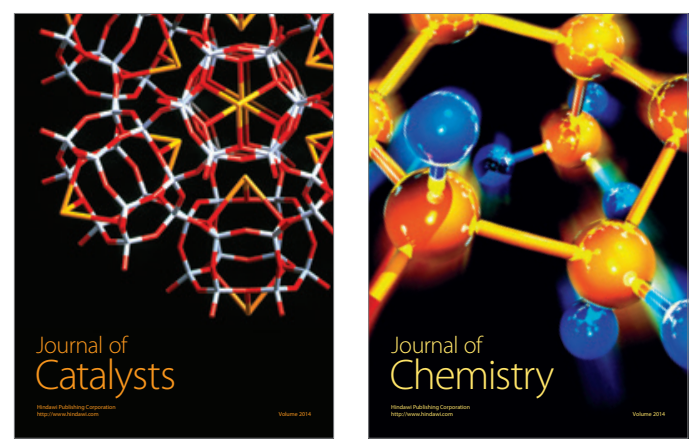
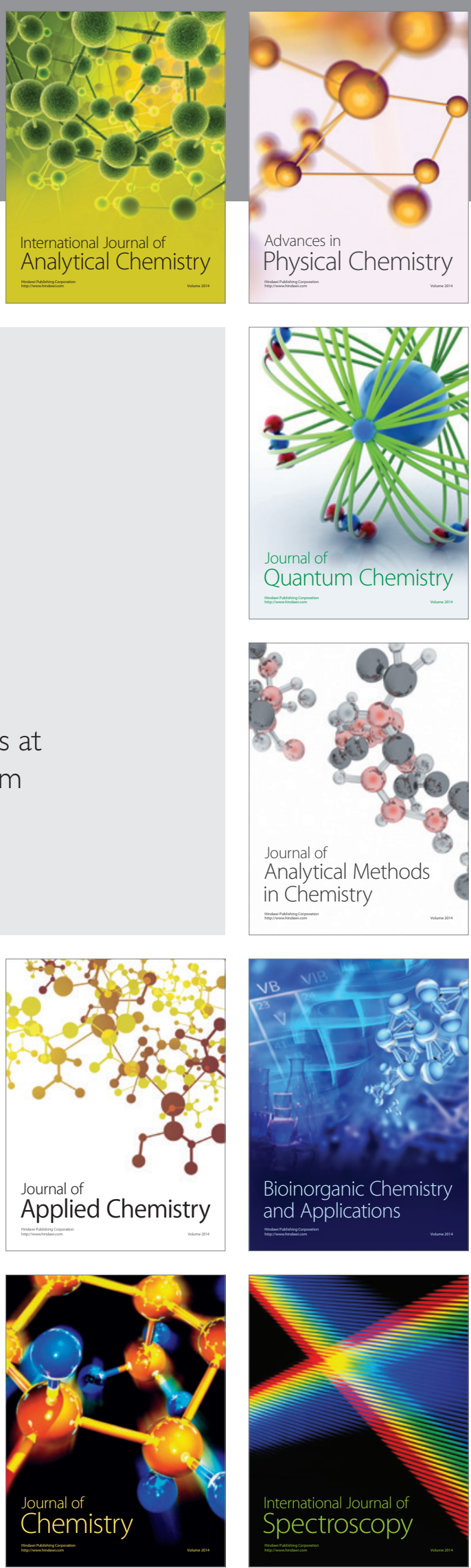